\title{
Throat Swab Procedure in Children
}

\author{
Çocuklarda Boğaz Sürüntüsü Örneği Alımı
}

\author{
Manolya Kara(ID) \\ Clinic of Pediatric Infectious Diseases, VM Medical Park Hospital, İstinye University Faculty of Medicine, İstanbul, Turkey
}

Cite this article as: Kara M. Throat swab procedure in children. J Pediatr Inf 2021;15(2):e122-e124.

\section{Introduction and General Information}

Acute tonsillopharyngitis is the most commonly seen infection of the childhood leading to hospital presentations. The agent of the disease is mostly respiratory tract viruses. The most frequent bacterial agent group is Group A streptococcus (GAS), and GAS infections in school-aged children between 5 and 15 years have been reported as 15-30\% among all tonsillopharyngitis agents. GAS pharyngitis can be observed in much younger children who are in contact with school-aged children. Corynebacterium diphtheriae, Neisseria gonorrhoeae, Arcanobacterium haemolyticum and anaerobe bacteria may also cause tonsillopharyngitis. While A. haemolyticum is a rare agent, it is substantial since it may lead to dengue-like rashes. Following the consumption of unpasteurized cow milk, Group C streptococcus may also be an agent of pharyngitis.

Although there are some clues in terms of tonsillopharyngitis etiology, it is not always possible to differentiate between viral and bacterial tonsillitis on just the basis of clinical findings. Therefore, it may be necessary to use laboratory diagnostic tests in select cases.

\section{Diagnosis of Bacterial Tonsillopharyngitis}

In order to detect Streptococcus pyogenes, direct diagnostic tests and bacteria culture can be performed on the throat swab sample.

\section{Sample Taking}

Pre-procedure

- Prepare the tongue depressor and sterile culture tube with swab (Figure 1).

- Perform hand hygiene.

- It is recommended to wear a surgical mask and gloves during the procedure, when necessary.

\section{Preparing the Patient}

- Prefer a well-lit room.

- Stand right in front of the patient.

- Make sure that the patient is in a comfortable position in front of the light source.

- Be careful with the tip of the sample strip not to touch anywhere besides the tonsillar region.

\section{Removing the Swab}

- Remove the swab from its protective package.

- Hold the strip firmly from its handle grip.

- Do not place the cotton strip on any surface after removing it from its protective package.

\section{Taking the Sample}

- Tell the patient to open his/her mouth as widely as possible and say "ahh".

- Direct the tip of the swab towards the tonsillar region.

\section{Yazışma Adresi / Correspondence Address \\ Manolya Kara \\ İstinye Üniversitesi Tıp Fakültesi, \\ Çocuk Sağlığı ve Hastalıkları Anabilim Dalı, İstanbul-Türkiye \\ E-mail: manolya_kara@yahoo.com}

Received: 26.04 .2021
OCopyright 2021 by Pediatric Infectious Diseases and Immunization Society. Available online at www.cocukenfeksiyon.org 
Table 1. Laboratory diagnosis in tonsillopharyngitis

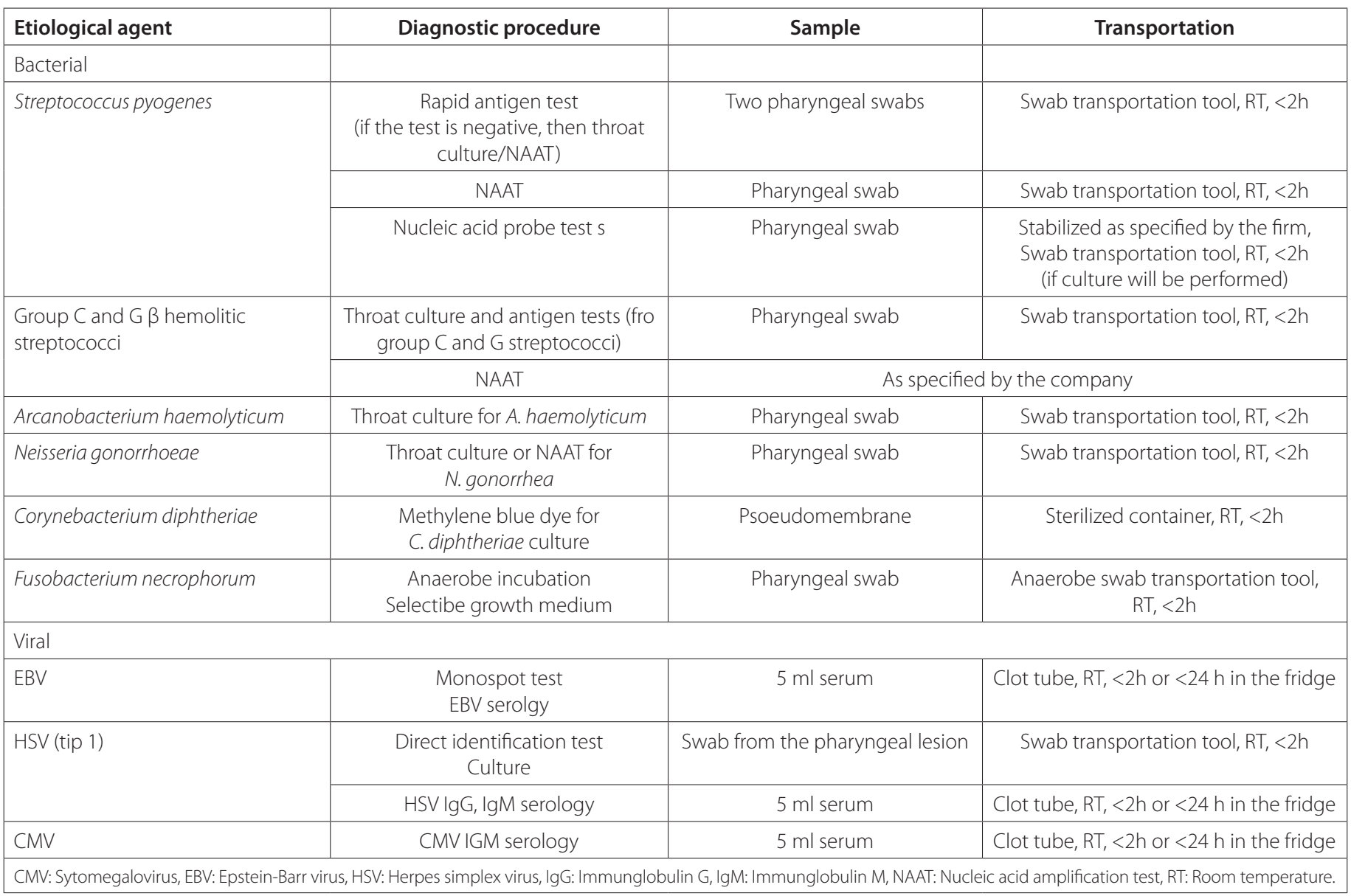

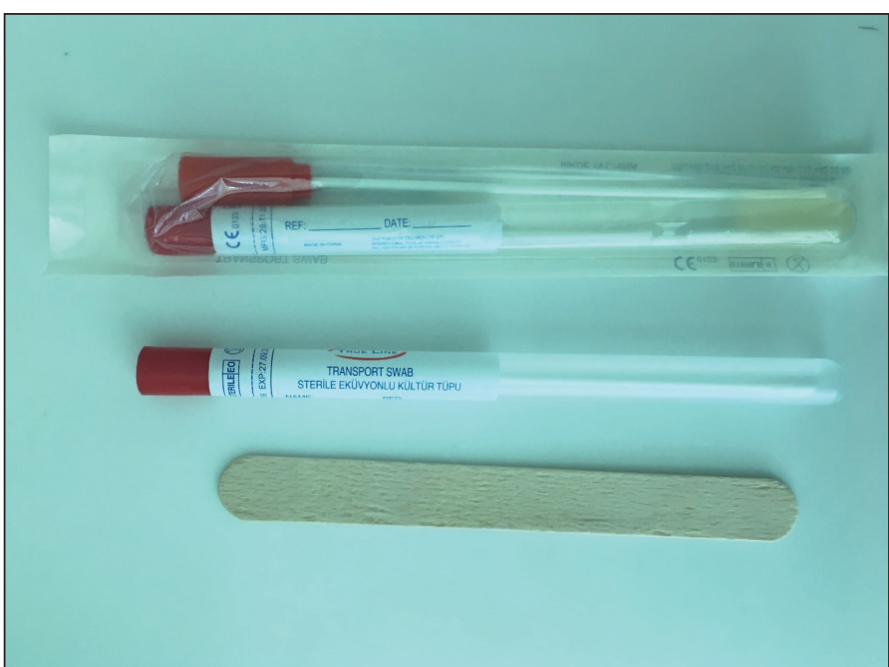

Figure 1. Culture tube with tongue depresssor amd sterile swab (mediated and dry type).

- Do not touch any part of the mouth including the tongue.

- After pressing on the tongue with the tongue depressor, take the sample without contacting the saliva by

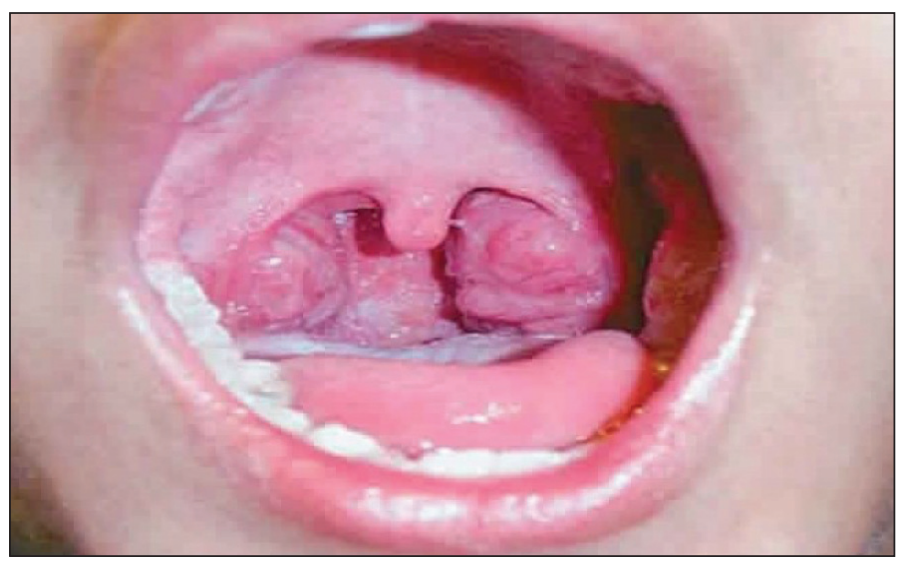

Figure 2. Posterior oropharyngeal view.

rubbing the swab onto both tonsils and the posterior pharynx (Figure 2).

- Remove the strip from the mouth avoiding contact with any surface.

\section{Post-procedure;}

- Using the aseptic technique, place the swab into the sterile tube. 
- Label the name and date of birth of the patient with the source and sample date on the tube.

- Culture inoculation of the sample must be performed within two hours. If not, the sample must be placed in the sample transport medium.

\section{Rapid Antigen Test}

Rapid antigen tests (RAT) for Group A streptococci are based on the extraction of the enzyme or acid of the antigen from the throat swab sample. Its specifity and sensitivity are $\geq 95 \%$ and $70-90 \%$, respectively. When high specifity and limited sensitivity of current tests are considered, positive RAT is useful in diagnosing GAS pharyngitis; however, a negative test does not eliminate GAS, and children and adolescents with RAT negativity must also undergo throat culture test.

\section{Throat Culture}

Throat culture, if applied correctly, has a specifity around $90-95 \%$ in diagnosing GAS pharyngitis. False negativity never exceeds $10 \%$ if culture is taken with the appropriate method and appropriate microbiological tests are performed in appropriate growth media in symptomatic cases. Pharyngeal isolation of Group A streptococcus does not differentiate the person with real streptococcal infection from the carriers of concurrent viral streptococcus.

Throat culture is usually performed in a $5 \%$ sheep blood agar. The culture is positive if the small gray colonies that have a surrounding beta hemolysis field are detected following an $18-24 \mathrm{~h}$ incubation at $35-37^{\circ} \mathrm{C}$. Cultures that result negative in the first 24 hours must be cultured for another 24 hours to maximize GAS growth. Throat culture can also identify Group $C$ and Group G streptococci and other bacteria like Arcanobacterium haemolyticum that much rarely cause pharyngitis.

\section{References}

1. Wald ER. Group A streptococcal tonsillopharyngitis in children and adolescents: Clinical features and diagnosis. https://www.uptodate. com (Accessed date: 8 April 2021). [CrossRef]

2. Miller JM, Binnicker MJ, Campbell S, Carroll KC, Chapin KC, Gilligan PH, et al. A Guide to Utilization of the Microbiology Laboratory for Diagnosis of Infectious Diseases: 2018 Update by the Infectious Diseases Society of America and the American Society for Microbiology. Clin Infect Dis 2018;67(6):e1-e94. [CrossRef]

3. Wilson ML. General principles of specimen collection and transport. Clin Infect Dis 1996;22(5):766-77. [CrossRef]

4. Lean WL, Arnup S, Danchin M, Steer AC. Rapid diagnostic tests for group A streptococcal pharyngitis: a meta-analysis. Pediatrics 2014;134:171. [CrossRef]

5. Cohen JF, Bertille N, Cohen R, Chalumeau M. Rapid antigen detection test for group A streptococcus in children with pharyngitis. Cochrane Database Syst Rev 2016; 7:CD010502. [CrossRef]

6. Shulman ST, Bisno AL, Clegg HW, et al. Clinical practice guideline for the diagnosis and management of group A streptococcal pharyngitis: 2012 update by the Infectious Diseases Society of America. Clin Infect Dis 2012; 55:e86. [CrossRef]

7. Bisno A.L. Practice Guidelines for the Diagnosis and Management of Group A Streptococcal Pharyngitis. Clin Infect Dis 2002;35:113-25. [CrossRef]

8. Smeltzer, S.C. Brunner \& Suddarth's Textbook of Medical-Surgical Nursing. $11^{\text {th }}$ ed. Lippincott Williams \& Wilkins: 2008. Philadelphia. [CrossRef] 